\section{Bauphase und erste Einrichtung des HITM}

\section{Die Lage}

Das Gelände des Asella Teaching Hospital und der angeschlossenen Medizinischen Fakultät befindet sich am Ortseingang der Stadt Asella. Im Zentrum des Komplexes steht das Krankenhaus mit seinen zumeist einstöckigen Gebäuden mit verschiedenen Stationen, Ambulanzen und Laboren, einer Apotheke, Wäscherei, einer Küche, Archiven und Büroräumen. Es handelt sich um eine sehr aktive und stetig wachsende Ausbildungsstätte für Medizinberufe. Neben Ärzten werden hier Pflegekräfte, Laboranten und Health-Officers ausgebildet. Letztere Berufsgruppe durchläuft eine dreijährige Ausbildung, die teilweise an das Medizinstudium angegliedert ist. Health-Officers dienen der medizinischen Basis-Versorgung im ärztlich unterversorgten Äthiopien in einer Stellung, die zwischen Pflegekraft und Arzt eingestuft werden kann.

Eine große moderne Bibliothek, Seminarräume und ein Hörsaalgebäude dienen der Ausbildung. Eine einfache Mensa und einige kasernenartige Schlafkomplexe mit Mehrbettzimmern stellen die Versorgung der Medizinstudenten sicher. Gerade hier ist die Infrastruktur den wachsenden Zahlen von Studenten nicht gewachsen. Die Medizinstudenten beklagen regelmäßig mangelhafte hygienische Bedingungen in ihren Wohnheimen und eine Unterversorgung durch die Mensa. Staatlicherseits werden derzeit Maßnahmen zur Verbesserung der Situation unternommen. Auch das Hirsch-Institut befindet sich auf dem Areal, in der Nähe des Krankenhauses und der Labore.

\section{Der Bau}

Finanziell wurde das Bauvorhaben teilweise durch eine Spende des Düsseldorfer Unternehmers Wolfgang Hirsch ermöglicht. Die Planung erfolgte in enger Zusammenarbeit von Professor Häussinger und seinen Mitarbeitern mit der Architektin Uta Groß, die an der Universität von Adama angestellt war und dort an Ausbau und Vergrößerung der Universität mitwirkte.

Die Planung sah ein Gebäude mit Büro-, Labor- und Untersuchungsräumen sowie einem Seminarraum vor. Sowohl der Labortrakt als auch der Seminarraum haben separate Eingänge. Für Patienten besteht auf der überdachten Terrasse genügend Raum für einen Wartebereich, es sind Außentoiletten vorhanden, und die Behandlungsräume verfügen über einen separaten Zugang von außen.

Etwas abseits wurde ein Generatorhaus zur späteren unabhängigen Stromversorgung errichtet, welche inzwischen in Betrieb genommen werden konnte. Auf einem Turm befindet sich ein 2.000 Liter fassender Wassertank, um von einer nicht immer zuverlässigen städtischen Wasserversorgung, zumindest zeitweise, unabhängig zu sein.

Aufgrund des raschen Wachstums verfügte die Universität über eine erfahrene Abteilung für Infrastruktur, die für uns auch den Aufbau des Instituts mit einer dort ansässigen, bekannten Baufirma vorantrieb.

Es handelt sich um ein einstöckiges Gebäude in Massivbauweise, das den modernen Erdbebenschutz-Richtlinien entspricht.

Viel Holz wird zum Gerüstbau verwendet; anstelle einer Schubkarre wird Material von zwei Personen getragen, und bei der Bauweise fällt 


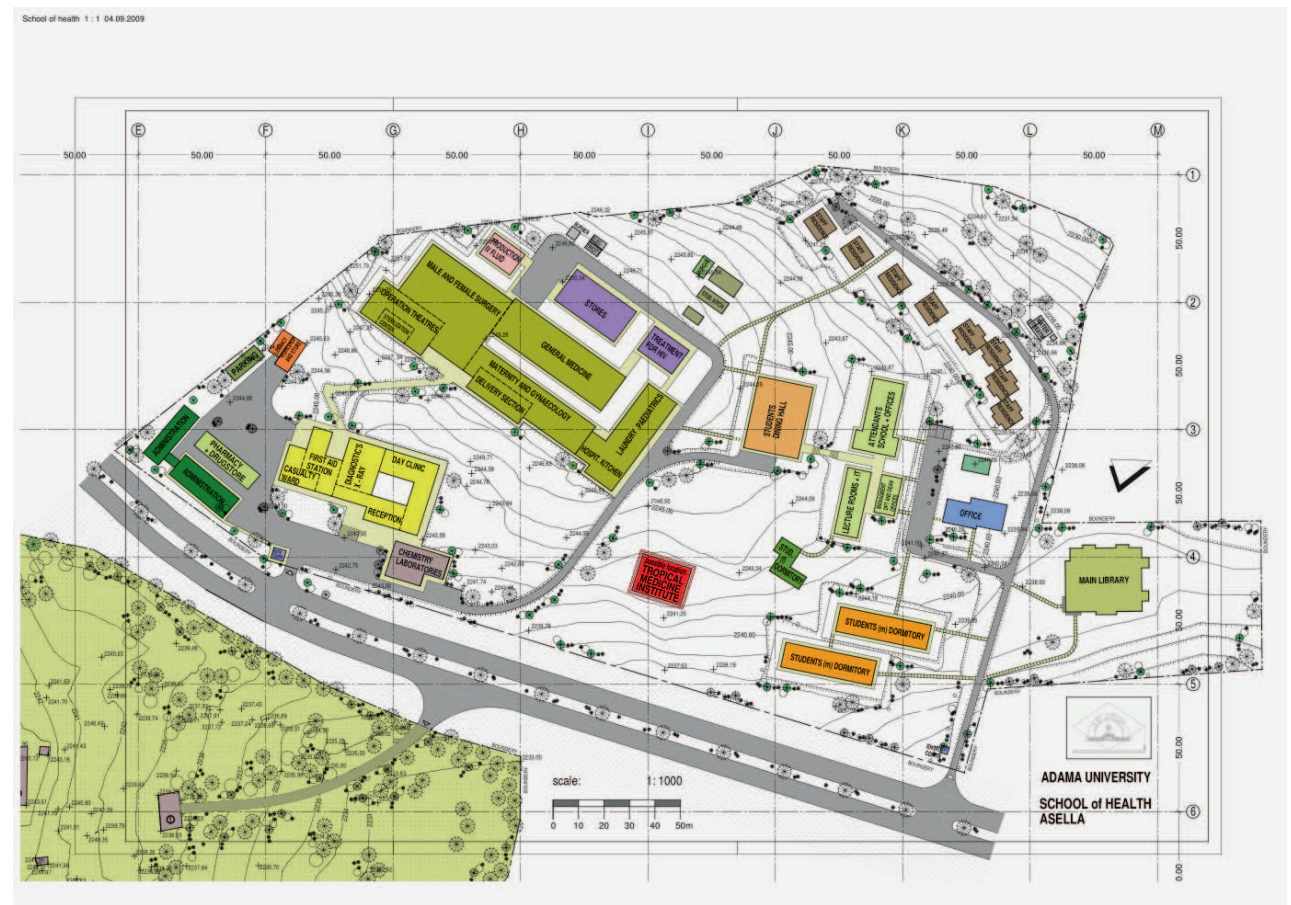

Lageplan des Krankenhauses in Asella mit Tropeninstitut (rot, Stand: 2009)



Grundriss des Instituts 


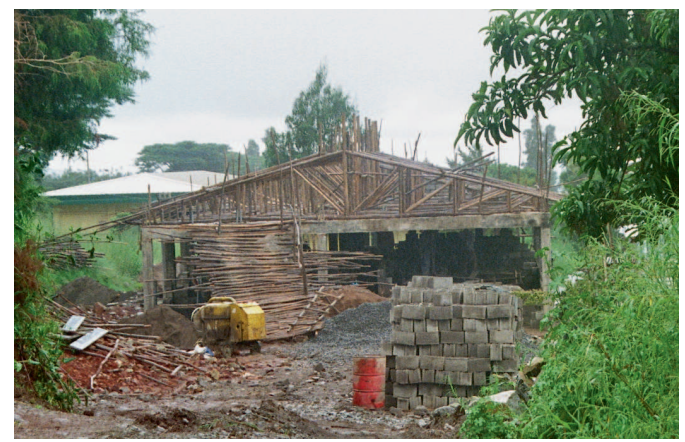

Rohbau des Instituts (2011)

auf, dass sämtliche Strom- und Wasserleitungen im Betonboden verschwinden. Letztendlich entstand ein Bau, der für lokale Bauverhältnisse herausragend war.

Eine Mitarbeiterin der Klinik für Gastroenterologie, Hepatologie und Infektiologie (Dr. Simone Kann) konnte über den Deutschen Akademischen Austauschdienst finanziert für ein Jahr im Krankenhaus arbeiten und somit die letzte Bauphase mitverfolgen und unterstützen. Hierzu gehörten unter anderem die Koordination des Aufbringens eines speziellen widerstandsfähigen Kunststoff-Bodenbelags in den Laborräumen und die Planung der Inneneinrichtung.

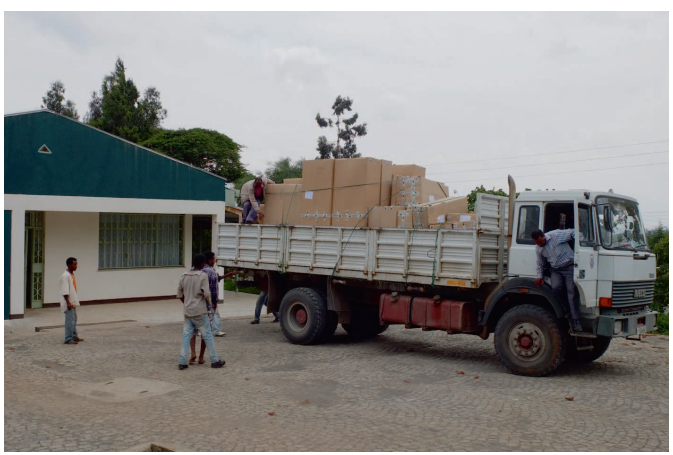

Die Labormöbel werden geliefert (2013)

\section{Inneneinrichtung}

Wie im Kooperationsvertrag vereinbart, übernahm der äthiopische Partner die Möblierung des Seminarraums und der Büroräume, wohingegen die Innenausstattung der Laborräume auf höchstem Qualitätsstandard von deutscher Seite getragen wurde.

Die Inneneinrichtung wurde durch eine staatliche Schreinerei in Asella angefertigt, die im Großbetrieb normalerweise Mobiliar für Schulen und Verwaltungsgebäude herstellt.

Die durch die Universität von Adama geplanten 30 Holzstühle für den Seminarraum wurden über das institutseigene Budget durch 30 moderne Polsterstühle ergänzt.

Gemäß den gehobenen Qualitätsanforderungen an die Laborausstattung wurden höchste Ansprüche an Stabilität, Passgenauigkeit und Oberflächen, die eine optimale Reinigung ermöglichen, gestellt. Staub und Durchzug würden die geplanten molekulargenetischen Untersuchungen unmöglich machen. Im gesamten östlichen Afrika war kein Produzent für Laboreinrichtung auf zufriedenstellendem Niveau zu finden.

Über entsprechende Empfehlungen wurde die Einrichtung bei einer Firma aus Dubai in Auftrag gegeben. Ein deutsch-äthiopischer Importeur verfolgte die Produktion und organisierte Verschiffung und Import des Containers der Labormöbel.

Aufgrund der hohen bürokratischen Hürden beim Import nach Äthiopien erreichte der Container den Bestimmungsort mit Verzögerung. Der Aufbau der Labormöbel durch zwei eingeflogene Mitarbeiter der Produktionsfirma aus Dubai dauerte eine knappe Woche.

Der Seminarraum wurde mit einem abschließbaren Bücherregal für eine kleine Bibliothek, 




Auch bei den Werkzeugen, hier ein Schweißgerät, wird improvisiert einem Whiteboard, einer Leinwand und einem Projektor ausgestattet.

Mit Zunahme der apparativen Ausstattung des Instituts wurden auch umfassende Maßnahmen zur Einbruchssicherung erforderlich. Die Glasscheiben waren dünn und ohne großen Widerstand zu brechen. Der Zaun zur Straße war nur zehn Meter entfernt und leicht zu erklimmen. Das Wachpersonal des Geländes bestand nur aus zwei mit Bambusstöcken bewaffneten Personen an jedem der beiden Haupttore.

Durch einen ortsansässigen Metallarbeiter wurde zur Erhöhung der Einbruchssicherheit mit Hilfe eines abenteuerlich anmutenden Schweißgeräts eine Vergitterung an Fenstern und Türen montiert.

Auch die Umgebung des Instituts nahm im Verlauf des Jahres 2012/13 Gestalt an. Der Vorplatz war bereits mit Kopfsteinpflaster belegt. Nach Fertigstellung des neuen Hörsaalgebäudes in direkter Nachbarschaft wurde das Pflaster durch das Institut bis dorthin erweitert. Die Grünflächen um das Gebäude wurden von Bauschutt und Gestrüpp befreit und Büsche und Blumen gepflanzt.

Die Anlage des Rasens brachte eine kleine Überraschung mit sich: Anstelle von Grassa- men wurden zwei große Säcke mit frisch geernteten Setzlingen geliefert, die noch am gleichen Tag verpflanzt werden mussten.

Da anfangs einige Baumängel bestanden, waren Nacharbeiten erforderlich. So kam es bei heftigem Regen anfangs zu Wassereintritt durch die Institutsfenster und -türen, welche nachträglich abgedichtet und neu lackiert werden mussten. Klemmende Türen mussten abgeschliffen, lose Türklinken neu befestigt werden, und weitere andere kleinere und größere Reparatur- und Wartungsarbeiten waren zu verrichten.

Hinzu kam, dass sich seit der Planung des Gebäudes die Anforderungen an Raumaufteilung und Funktion der einzelnen Räume geändert hatten. So musste ein Schaltraum zwischenzeitlich in ein Büro umgewandelt werden, ein Laborraum wurde durch eine Schleuse in einen Reinraum umgewandelt, ein WC wurde in einen Generatorraum umgewandelt und ein Generatorraum in eine Werkstatt.

Im Frühling 2018, als das Mikrobiologielabor installiert wurde, folgten weitere Änderungen in der Aufteilung. Räume für einen Autoklaven, eine Sicherheitswerkbank, Brutschränke, eine Nährmedienküche und Waschgelegenheiten mussten eingerichtet werden.

Ein nicht unerheblicher Teil der Arbeiten wurde in Eigenleistung der deutschen Mitarbeiter sowie mit gelegentlicher Unterstützung eines in der Nachbarschaft lebenden GIZ-Mitarbeiters verrichtet. Für andere Dinge konnten auf Empfehlung regionale Handwerker gewonnen werden, welche teilweise durch internationale Organisationen ausgebildet waren und sehr ordentliche Arbeit leisteten.

Letztendlich ist ein multifunktionales Institut entstanden, in dem Lehre, Forschung, Verwal- 
tung, klinische Untersuchung und Behandlung unter einem Dach möglich sind.

Durch unermüdliche Bemühungen des Institutsgründers und Direktors, Professor Häussinger, konnte zum Aufbau und der Einrichtung des Instituts Unterstützung von der Gesellschaft der Freunde und Förderer der Heinrich-Heine-Universität e. V., der Leber-Liga zur Förderung und Unterstützung chronisch Lebererkrankter e. V. und dem RotaryClub Düsseldorf-Süd gewonnen werden.

\section{Stromversorgung}

Immer wieder kommt es in Asella zu Stromausfällen, die häufig mehrere Stunden bis Tage andauern. Ohne Strom für Projektor, Laborgeräte und Computer ist eine Arbeit im Institut nicht möglich. Sensible Laborgeräte leiden unter Spannungsschwankungen und ungeplanten Unterbrechungen. Noch wichtiger ist jedoch die ununterbrochene Versorgung der Kühltruhen. Bei einer Unterbrechung der Kühlkette kann die Arbeit von Monaten zunichte gemacht werden.

Eine erste Notstromversorgung erfolgte mittels eines kleinen $3 \mathrm{~kW}$-Dieselaggregats, welches durch die Institutsmitarbeiter, außerhalb der Dienstzeiten durch einen Wachmann, in

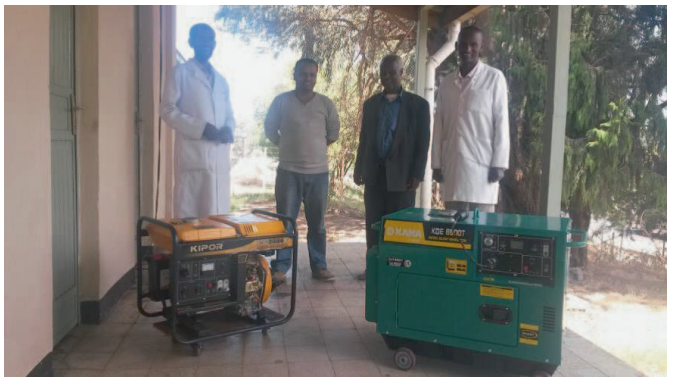

Die zwei Generatoren, welche in der Anfangszeit zur Überbrückung von Stromausfällen dienten. .

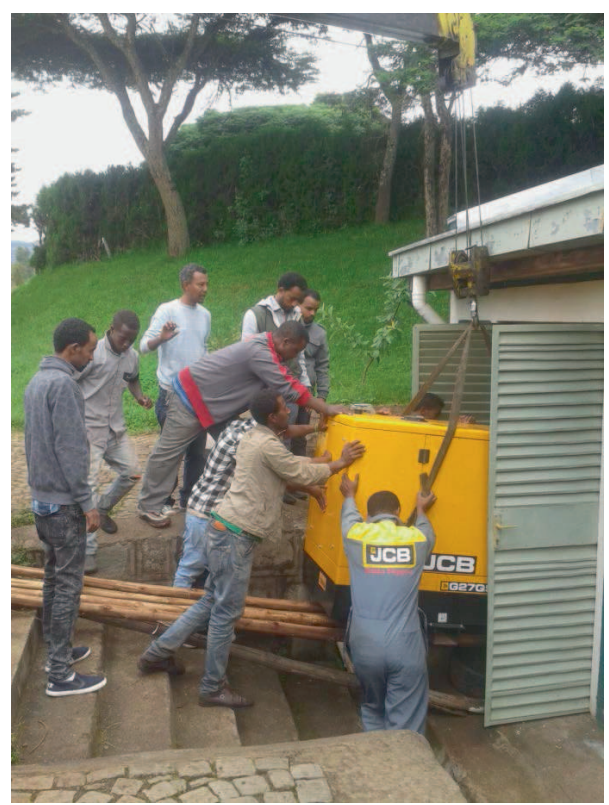

... wurden inzwischen durch ein größeres Modell ersetzt

Betrieb genommen wurde. Für den Fall eines Ausfalles stand für die Aufrechterhaltung der Kühltruhen ein kleineres Benzin-Aggregat zur Verfügung. Ein leistungsfähiger Generator zur Gewährleistung einer lückenlosen Stromversorgung des gesamten Instituts wurde Mitte 2016 mit freundlicher Unterstützung des Rotary-Clubs Düsseldorf-Süd installiert.

\section{Inventar}

Bereits in der Bauphase konnte ein vom Ministerium für Gesundheit, Emanzipation, Pflege und Alter des Landes Nordrhein-Westfalen finanziertes modernes Duplex-Ultraschallgerät $\left(\right.$ GE Vivid $\left.{ }^{\circledR}\right)$ mit drei Schallköpfen nach Asella transportiert werden. Nur etwas größer als ein Laptop eignet es sich sehr gut für Untersuchungen am Krankenbett. Regelmäßig werden 
die deutschen Kollegen von äthiopischen Ärzten und Studenten mit dem Gerät zur diagnostischen Hilfe und zu fachmännischem Rat angefordert. Inzwischen wurden mehrere äthiopische Internisten und ein Pädiater mit diesem Gerät in der Ultraschalluntersuchung des Bauchraums und des Herzens fundiert ausgebildet.

Mittlerweile erreichte ein zweites größeres Ultraschallgerät als Spende aus Deutschland das Institut und ist im dortigen Sonographieraum fest installiert.

Die Beschaffung von Laborgeräten und die regelmäßige Versorgung mit entsprechenden Verbrauchsmaterialien stellt eine der größeren logistischen Herausforderungen im Hirsch-Institut dar. Der äthiopische Markt für medizinisches Material ist sehr begrenzt, und beim Import treten regelmäßig bürokratische Hindernisse auf.

Der Erwerb der ersten Laborgeräte, eines Photometers und eines Koagulometers zur Untersuchung verschiedener Blut- und Gerinnungseiweiße erfolgte durch einen der wenigen Importeure für Medizinprodukte in Äthiopien. Das vorrätige Angebot, aber auch Schwierigkeiten beim Import von Ware, limitieren jedoch gelegentlich die Versorgung des Instituts. Später wurde über einen anderen Anbie-

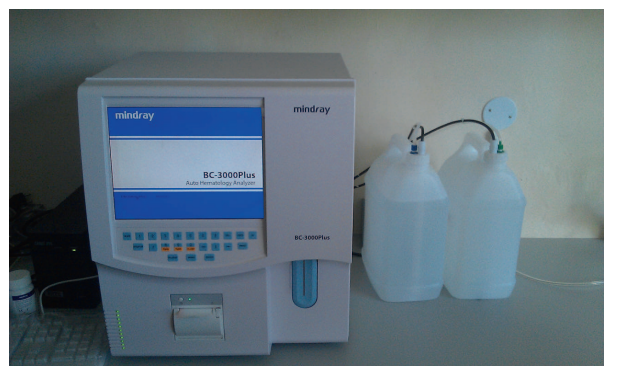

Das neue Hämatologie-Gerät

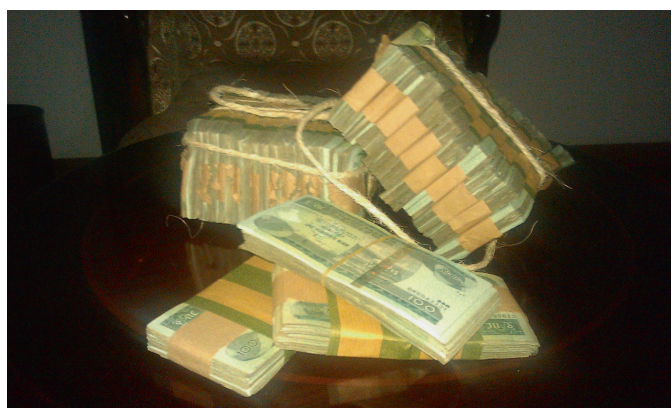

Bezahlt wird in bar: Das Geld für das Laborgerät. Der größte äthiopische Geldschein ist etwa $3 €$ wert

ter zur Vervollständigung des Basislabors noch ein Hämatologie-Gerät zur Untersuchung des großen Blutbildes erworben.

Die gute Beziehung zur Universität von Adama und wiederum deren Beziehungen zu den äthiopischen Behörden und Ämtern waren beim Import oft hilfreich und notwendig.

Die meisten zusätzlich angeschafften und verwendeten Geräte konnten durch Spenden verschiedener Industrieunternehmen finanziert werden. So wurden zwei Zentrifugen und ein PCR-Gerät (Mastercycler ${ }^{\circledR}$ ) von der Firma Eppendorf, zwei Elecsys ${ }^{\circledR} 2010$ Blutanalysatoren von der Firma Roche und ein Realtime Multiplex-PCR-Gerät von der Firma Qiagen gespendet. Nach Erhalt einer Forschungsförderung durch die Else Kröner-Fresenius-Stiftung wurde die Ausstattung des Labors mit einem GeneXpert ${ }^{\circledR}$, z. B. für die Tuberkulose-Diagnostik, ermöglicht. Ein weiterer Ausbau der Laborkapazitäten mit einer speziellen Zentrifuge, einem Ultra Deep Freezer (-80 C) sowie einer Werkbank zur sicheren und sauberen Verarbeitung biologischer Proben konnte durch eine Spende des Rotary-Clubs Deutschland ermöglicht werden. 


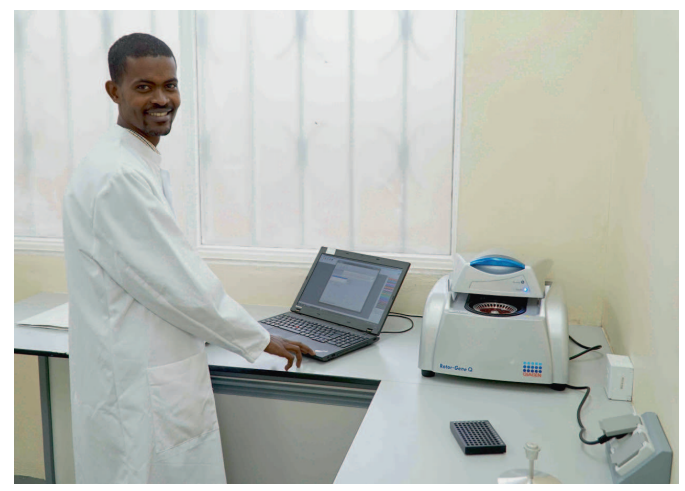

Der Parasitologe des Instituts M. Getachew mit dem neuen PCR-Gerät

Ein automatisches Blutkultur-Gerät (BacT/ ALERT $^{\circledR}$ 3D 120) wurde aus Forschungsmitteln des Bundesministeriums für Bildung und Forschung angeschafft und 2018 in Betrieb genommen.

Für Studienzwecke wurde ein durch die HeinzAnsmann-Stiftung für AIDS-Forschung finanziertes Fibroscan ${ }^{\circledR}$-Gerät eingeführt, welches durch die Haut als Elastographie-Verfahren die Steifigkeit der Leber messen kann. Hiermit können Lebererkrankungen wie Leberfibrose oder Leberzirrhose frühzeitig und nicht-inva-

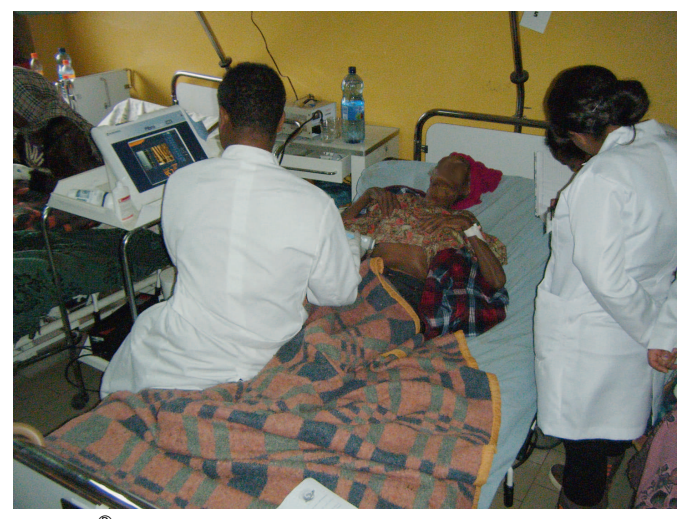

Fibroscan ${ }^{\circledR}$-Gerät im stationären Einsatz siv erkannt werden. Zum jetzigen Zeitpunkt ist dieses sicher das einzige Gerät in Äthiopien, vielleicht sogar im östlichen Afrika.

Für die Errichtung des Instituts, die Einrichtung und den täglichen Betrieb ist das Institut auf die großzügigen Spenden und Drittmittel angewiesen, welche mit unermüdlichem persönlichem Einsatz durch Professor Häussinger akquiriert wurden und weiterhin werden.

\section{Personal}

Mit Fertigstellung des Gebäudes kam aus der Düsseldorfer Klinik für Gastroenterologie, Hepatologie und Infektiologie Matthias Breuer als Instituts-Koordinator nach Asella. Im Vergleich zu seiner über den DAAD (Deutscher Akademischer Austauschdienst) entsendeten Vorgängerin hatte er keinen primären Auftrag im Krankenhaus, so dass er sich auf den weiteren Aufbau des Instituts konzentrieren konnte. Als Facharzt für Innere Medizin nahm er jedoch auch an Besprechungen und Visiten teil und wurde insbesondere zur sonographischen Diagnostik zurate gezogen.

Rasch bestätigte sich die Vermutung, dass eine direkte Anstellung von äthiopischem Personal durch die Universität Düsseldorf nicht möglich ist bzw. kaum zu bewältigende bürokratische Hürden aufwerfen würde. Dies war bereits im Kooperationsvertrag berücksichtigt worden, und die Bereitstellung einiger Arbeitskräfte durch den äthiopischen Partner war festgeschrieben. Im Rahmen der partnerschaftlichen Zusammenarbeit und der Stellung des Hirsch-Instituts als Kooperationsprojekt unter deutscher Leitung erfolgt nun die Einstellung von Personal für das Institut formal durch die äthiopischen Partner, allerdings organisiert 


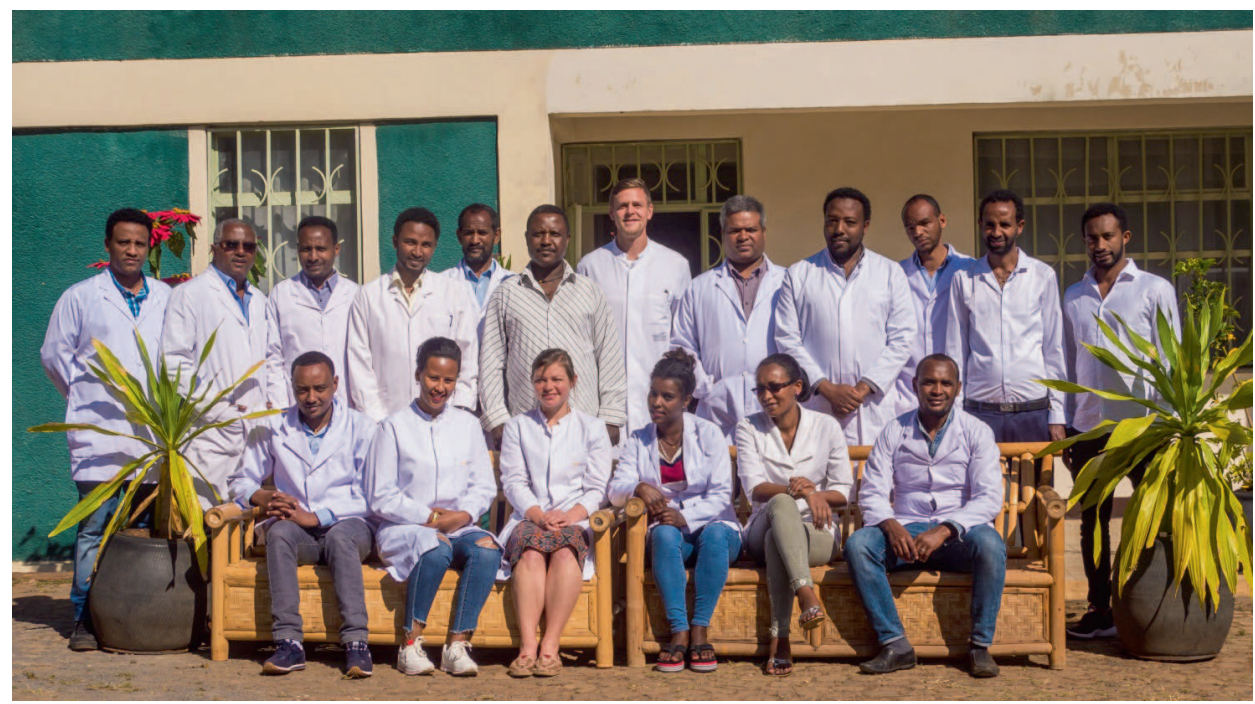

Das Team des HITM 2018

und weitgehend bestimmt durch die Koordinatoren des Instituts vor Ort.

Für den Regelbetrieb des Instituts wurden zunächst ein Institutsverwalter, ein Verwaltungsassistent, zwei Laboranten, zwei Wächter und drei Reinigungskräfte eingestellt. Für die anlaufenden Studien folgte die Einstellung von zwei Krankenschwestern.

Personaleinstellungen setzen in Äthiopien je nach Posten eine lokale, regionale oder nationale Stellenausschreibung voraus. Wer sich bis zum festgelegten Annahmeschluss mit vollständigen Bewerbungsunterlagen registriert hat, wird zum Auswahlverfahren zugelassen. Eine zuvor bestimmte Auswahlkommission trifft in einem kompliziert anmutenden Prozess nach möglichst objektiven Kriterien eine Entscheidung über die Neueinstellung. Dem Institutskoordinator ist durch dieses Verfahren die Möglichkeit der Auswahlfreiheit genommen. Diesem Verfahren liegt äthiopisches
Recht zugrunde, mit dem Vetternwirtschaft und Korruption verhindert werden sollen.

Zum Personal des Instituts gehört ein Fahrer, der ebenfalls per Kooperationsvertrag von der äthiopischen Seite gestellt wird. Der erste Fahrer, Ato Shiferaw, ging zwischenzeitlich in den Ruhestand und wurde durch Ato Wendwesen ersetzt, einen gleichermaßen umsichtigen und gewissenhaften Fahrer. Er steht den Mitarbeitern des Instituts rund um die Uhr zur Ver-

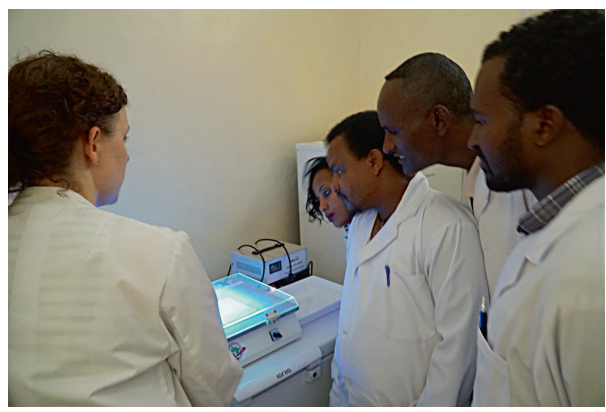

PCR-Ausbildung des Laborteams 


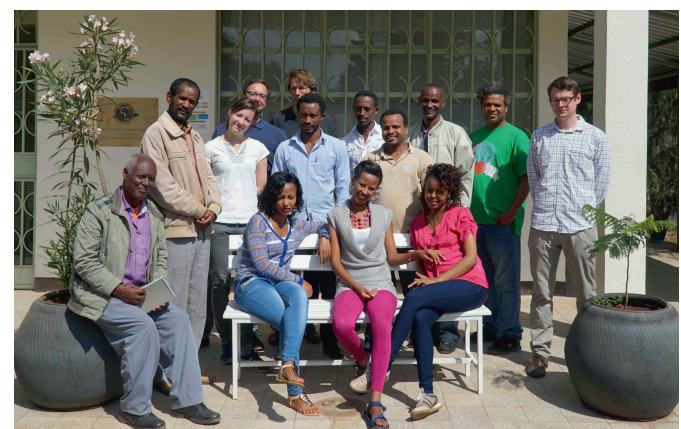

Studienpersonal des HITM im März 2015

fügung und kümmert sich liebevoll um „seine Autos“. Auch übernimmt er kleinere Reparaturen selbstständig.

Mit zunehmender Studientätigkeit wurde der Personalstamm des Instituts weiter ausgebaut. Drei akademische Mitarbeiter (zwei Mikrobiologen und ein Parasitologe), drei Health Officers, eine Hebamme und eine zusätzliche Laborantin wurden eingestellt.

Seit August 2014 finanziert die Heinz-Ansmann-Stiftung für AIDS-Forschung die Stelle eines zweiten deutschen Arztes als Koordinator und Studienarzt in Asella. Hierfür konnten seit dem Sommer 2014 mehrere Ärzte von verschiedenen Standorten in Deutschland gewonnen werden. Durch gleichzeitige Entsendung von zwei Ärzten wird nun der gewachsenen Personalverantwortung, den organisatorischen Herausforderungen, der zunehmenden Studientätigkeit des HITM, aber auch der Mitarbeitersicherheit Rechnung getragen. Aktuell verfügt das Institut über insgesamt 26 teils in Vollzeit, teils in Teilzeit beschäftigte Mitarbeiter. Neben den beiden deutschen Koordinatoren arbeiteten im Sommer 2018 drei äthiopische Akademiker (Parasitologie und Mikrobiologie), ein Verwalter, ein Verwaltungsassis- tent, drei Study Nurses, drei Laboranten, vier Health Officers, zwei Data Clerks, ein Fahrer, zwei Nachtwächter und vier Reinigungskräfte für das HITM. Mehrere Ärzte des Krankenhauses sind auf Honorarbasis und aus fachlichem Interesse an verschiedenen Studien beteiligt.

\section{Kommunikation von Kontinent zu Kontinent}

Die Absprache für weitere Planungen zwischen der Institutsleitung in Düsseldorf und den Mitarbeitern vor Ort in Asella stellt aufgrund der räumlichen Distanz und der teilweise unzuverlässigen Telefon- und Internetverbindung das Team des Instituts immer wieder vor Herausforderungen.

Die Anfertigung und Übersendung monatlicher „Asella-Berichte“ ermöglicht es dem Direktor des HITM, Herrn Professor Dr. Häussinger, einen umfassenden Überblick über alle aktuellen Tätigkeiten und Ereignisse in Äthiopien zu erlangen, so beispielsweise bezüglich der Fortschritte im medizinisch-wissenschaftlichen Bereich, der Logistik (Personalangelegenheiten, Gebäude, Fahrzeuge etc.) und der finanziellen Situation. Die Sach- und Personalkosten zum Betrieb und Erhalt des Instituts belaufen sich auf ca. $100.000 €$ pro Jahr.

\section{Fahrzeuge}

Dem Institut stand seit der Bauphase und Einrichtung ein eigenes Allradfahrzeug (Toyota Landcruiser, Baujahr 1996, 3,01 Turbodiesel) zur Verfügung.

Der Wagen wurde von einem Kollegen aus einer Nicht-Regierungsorganisation im Auftrag des Direktors des Instituts erworben. Nicht-Regierungsorganisationen, Unternehmen wie die 


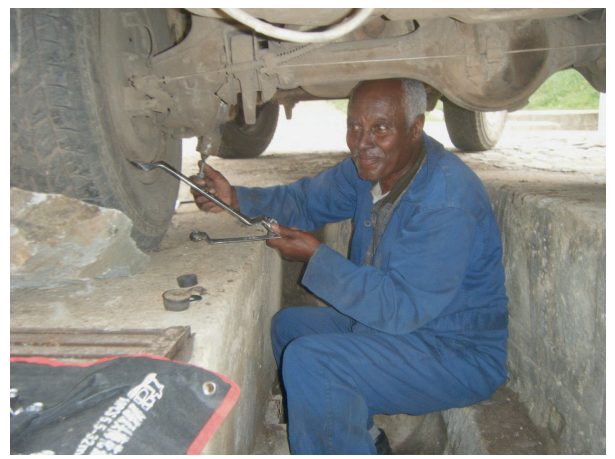

Der Fahrer Shiferaw bei Wartungsarbeiten am Institutsfahrzeug

GIZ und auch der DAAD müssen für importierte Fahrzeuge glücklicherweise keinen Einfuhrzoll entrichten. Der übliche Zoll würde das Doppelte des Werts des Wagens betragen. Da zukünftige Koordinatoren nicht mehr dieses Zollprivileg haben werden, wäre bei einer Übertragung der Fahrzeughaltung auf den nachfolgenden Institutskoordinator dieser Importzoll nachträglich in voller Höhe fällig geworden. Auch hier half die Kooperation mit der äthiopischen Universität: Der Wagen wurde mit einem Vertrag zur exklusiven Nutzung durch das Hirsch-Institut an die Adama-Universität gespendet. Auch wenn dieser Prozess einfach klingt, so dauerte er doch sechs Monate und bedurfte vieler Briefe und Fahrten zu Behörden nach Addis Abeba, um eine $\mathrm{Zu}-$ lassung des Wagens im Namen der Universität von Adama zu erreichen. Bis dahin blieb dem Institutskoordinator zumeist nichts anderes übrig, als den öffentlichen Nah- und Fernverkehr Äthiopiens zu nutzen.

Mit Präsenz eines zweiten deutschen Arztes und dem Beginn weiterer Studien wurde ein zweiter Wagen erforderlich.

Mit dem bisherigen Fahrzeug konnten kaum mehr als zwei Personen über längere Strecken

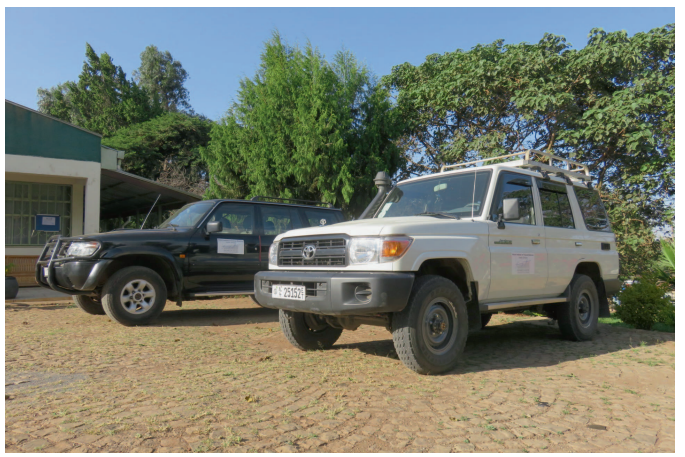

Die neuen Autos des Instituts

transportiert werden, größere Lasten fanden im kleinen Kofferraum keinen Platz und mussten auf dem Dachgepäckträger befestigt werden. Außerdem häuften sich die Reparaturen an dem fast 20 Jahre alten Fahrzeug. Die Wahl fiel daher auf ein größeres viertüriges Fahrzeug. Im Dezember 2014 gelang der Erwerb eines neuwertigen Nissan Patrol (Baujahr 2000, 3,0 1 Turbodiesel) von einem das Land verlassenden deutschen Mitarbeiter der GIZ. Auch dieses Fahrzeug wurde mit entsprechendem exklusivem Nutzungsvertrag an die äthiopische Universität gespendet.

Nachdem das alte Fahrzeug zunehmend Probleme machte und sich Reparaturen häuften, wurde ein neues Fahrzeug erforderlich. Durch eine weitere Spende und die Unterstützung durch den äthiopischen Partner wurde im Herbst 2017 der Erwerb eines fabrikneuen Toyota Land Cruiser TDI 2.0 ermöglicht, welcher Anfang 2018 in Betrieb genommen werden konnte und seither zuverlässige Dienste auf und im Notfall auch abseits der äthiopischen Straßen leistet. Das alte Fahrzeug konnte daraufhin an die Medizinische Fakultät der Arsi-Universität übergeben werden, wo es weiterhin im Dienst der Patientenversorgung steht. 


\section{Täglich frische Eier}

Einen Supermarkt, wie wir ihn kennen, gibt es in Asella nicht. Die größten Lebensmittelgeschäfte bestehen aus einem ca. $10 \mathrm{~m}^{2}$ großen Raum mit einer Theke, mit diversen Lebensmitteln in mehr oder weniger gefüllten Regalen. Die angebotenen Eier, die meist in Drahtkörben neben der Theke hängend aufbewahrt werden, sind deutlich kleiner als bei uns. Nicht selten kommt es vor, dass man nach Kauf eines der meist aus der Hühnerschar hinter dem Lebensmittelladen stammenden Eier die verschiedenen Stufen der Embryonalentwicklung eines Vogels studieren kann. Aus diesem Grund wurde entschieden, eine eigene Hühnerhaltung zu etablieren, um die Versorgung mit frischen Eiern sicherzustellen.

In Asella werden schicke zweistöckige Hühnerhäuser gezimmert - mit verschließbarem Eingang, Blechdach und Klappen, durch welche die gelegten Eier nach außen rollen. Vom Eselskarren geliefert, fand das Hühnerhaus seinen Platz im hinteren Teil des Gartens eines der Wohnhäuser. Mit großem Eifer half Gesagne, einer unserer Nachtwächter, beim Anfertigen eines angemessenen Auslaufes aus Maschendraht. Auch bei der Auswahl legefreudiger Hühner auf dem lokalen Markt waren wir auf die Hilfe von Gesagne angewiesen - uns Deutschen ist das nötige Gespür zur Identifikation gesunder Legehennen verloren gegangen.

Nachdem die neuen Mitbewohner ihr Freigehege innerhalb einer Woche komplett abgegrast hatten und damit begannen, sich selber in die Quere zu kommen (Festlegen der „Hackordnung"), musste Abhilfe geschaffen werden. Das gesamte Grundstück wurde ringsum mit Hühnerdraht eingezäunt. Die Hühner hatten von nun an den ganzen Tag freien Auslauf im Garten. Und es gibt täglich frische Eier.

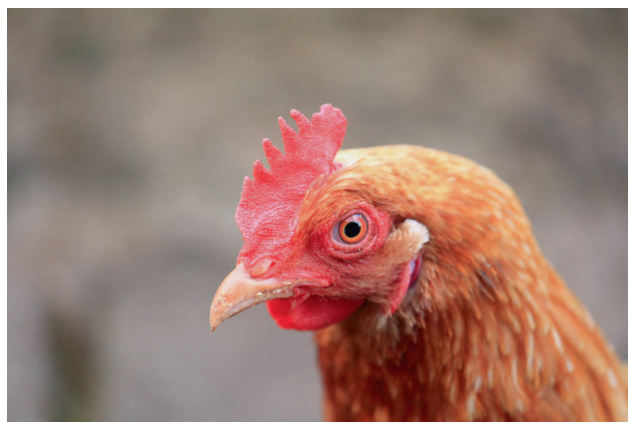

Eines der Haushühner im Garten 


\section{Tüpfelhyänen}

Hyänen sind doch Aasfresser! Ausnahme: Die in Äthiopien vorkommenden Tüpfelhyänen, die sich vorrangig von der Jagd ernähren. Die Wohnstätten der Institutsmitarbeiter liegen in Ardu, einem Außenbezirk von Asella, angrenzend an bewirtschaftete und wilde Natur. Fast jede Nacht hört man die typischen uuuuuiiiip!-Laute durch die ansonsten stille Nacht klingen. Wenige hundert Meter hangabwärts befinden sich die Schlafhöhlen der Raubtiere.

Es sei in den letzten Jahren vorgekommen, dass unvorsichtige Wanderer, die über Nacht ungeschützt im Freien genächtigt haben, Opfer von Hyänen wurden. Auch Studenten des Universitäts-Campus im nahe gelegenen Adama seien bereits angegriffen worden. Schwer zu bewerten ist die äthiopische Volksweisheit, dass man als ausgewachsener Mensch vor einem Angriff von Hyänen keine Angst zu haben braucht, solange sie nicht in Gruppen von sechs oder mehr Tieren auftauchen. In der äthiopischen Stadt Harar werden Hyänen sogar gemäß einer Legende als Retter der Stadt verehrt und täglich mit Schlachtabfällen und Ähnlichem gefüttert.

Bislang wurden von unseren Mitarbeitern nur einzelne Tiere gesichtet, nachts vor den Scheinwerfern des Autos, als neugieriger Begleiter auf den Hängen des Mt. Chilalo während einer Wanderung oder selten in den Abendstunden in der Umgebung der Wohnhäuser. Aber Respekt einflößend sind die Tiere schon, vor allem wenn sie völlig unbeeindruckt von Menschen mit ihren überdimensionalen Vorderläufen und Köpfen am Auto vorbeigaloppieren.

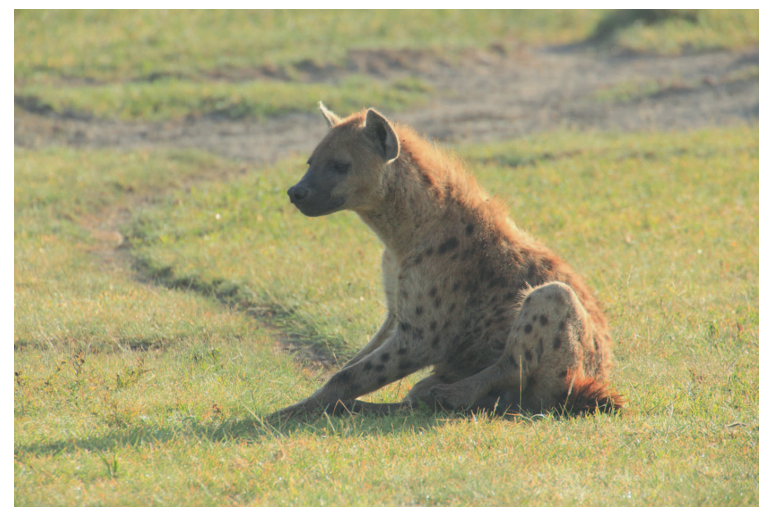

Junge Tüpfelhyäne 


\section{Straßenverkehr in Äthiopien}

In Äthiopien herrscht Rechtsverkehr. In der täglichen Praxis wird der Rechtsverkehr jedoch nur als Empfehlung angesehen. Darüber hinaus besteht Gerüchten zufolge sogar ein Rechtsfahrgebot auf zweispurigen Straßen. Dies ist jedoch praktisch nicht durchsetzbar, da bei - meist innerorts gelegenen - zweispurigen Straßen üblicherweise die rechte Spur durch anhaltende Minibusse und Fußgänger genutzt wird, welche gerne auch zwecks einfacherer Kommunikation in Viererreihen die Straße nutzen. Im Schritttempo bergauf fahrende LKW werden, wann immer sich Platz bietet, rechts überholt. Im Zuge des wirtschaftlichen Aufschwunges werden immer mehr Straßen asphaltiert und ermöglichen so schnelleres Fahren. An die Veränderungen und Gefahren, die ein rascherer Verkehrsfluss mit sich bringt, müssen sich viele, vor allem die Kinder, erst gewöhnen. Und so steht inzwischen auch die schulische Verkehrserziehung auf dem Stundenplan. Auf den Straßen muss man ständig beachten, dass jederzeit Kinder oder Erwachsene unvermittelt die Straße kreuzen können. Ein großes Verkehrshindernis stellen die Vierbeiner dar: Streunende Hunde gehören dabei noch zu den aufmerksameren Verkehrsteilnehmern. Viele Äthiopier besitzen Nutztiere wie Schafe, Ziegen oder Rinder, ohne über entsprechendes Weideland zu verfügen. Die Tiere grasen häufig am Rand der Straße und überqueren diese spontan, um an das Gras auf der anderen Seite zu gelangen. Auch ganze Viehherden werden häufig entlang der Hauptverkehrsstraßen zu frischem Weideland getrieben.

Eine Prüforganisation wie in Europa, die die Sicherheit der am Straßenverkehr teilnehmenden Kraftfahrzeuge überwacht, gibt es bislang in Äthiopien nicht. Es liegt in der eigenen Verantwortung der Fahrzeugbesitzer, die Sicherheit und Funktionsfähigkeit der Fahrzeuge aufrechtzuerhalten.

In der in Äthiopien das ganze Jahr über gegen 18:00 Uhr einsetzenden Dunkelheit zu fahren, ist den Mitarbeitern vieler Hilfsorganisationen aus Sicherheitsgründen untersagt. Fahrzeuge mit schlecht eingestellten Scheinwerfern blenden, vorausfahrende Fahrzeuge verfügen über kein funktionierendes Rücklicht, langsam fahrende Pferdefuhrwerke sind gänzlich unbeleuchtet und nachts kaum auszumachen.

Mit etwas Eingewöhnung und Aufmerksamkeit kann man aber natürlich auch als Mitteleuropäer gefahrlos kürzere Strecken mit dem Auto zurücklegen. 




Gegenverkehr auf dem Land

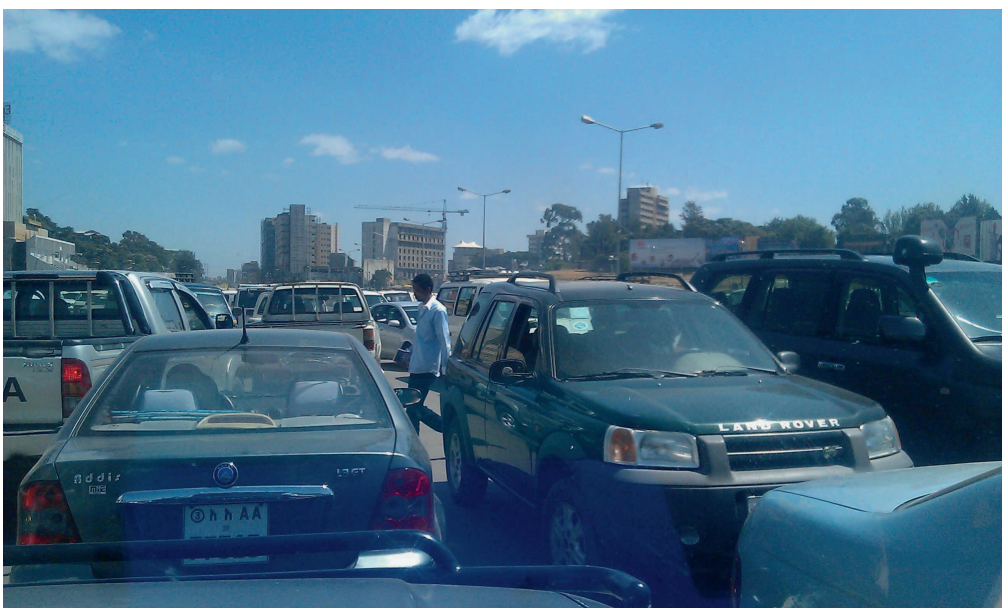

Straßenverkehr auf dem Meskel Square in Addis Abeba - gefahren wird, wo gerade Platz ist 


\section{Bautätigkeit}

Wer mit dem Flugzeug in Addis Abeba landet, findet ein Land im Umbruch vor. Überall entstehen neue Straßen, Bahnlinien und Gebäude. Besonders auffällig sind die Baugerüste und Verschalungen von oft auch sehr hohen Gebäuden. Diese bestehen üblicherweise aus Eukalyptusholz, welches zur Stabilität des Gerüstes mit Seilen gesichert und verstrebt wird. In der Regel werden die benötigten Baumaterialien per Hand in die höheren Stockwerke transportiert. Dabei fällt auf, dass die schwere körperliche Arbeit häufig von Frauen verrichtet wird. Schubkarren sind selten; größere Lasten werden meist von zwei Arbeitern auf einer einfachen Trage transportiert. Mit diesen einfachen Mitteln wird der äthiopische Aufschwung und der Ausbau der Infrastruktur initiiert, mit dem Ziel, der rasch wachsenden Bevölkerung und den Bedürfnissen der Wirtschaft gerecht zu werden. Für den rasanten Ausbau zählen im Wesentlichen zwei Argumente: Geschwindigkeit und Kosteneffizienz!

Seit vielen Jahren werden Anstrengungen unternommen, eine fundierte Ausbildung in handwerklichen Berufen zu implementieren. Vor der Zeitenwende gab es hierfür Unterstützung aus der DDR, später wurde die Hilfe durch internationale Organisationen geleistet, wie z. B. der GIZ oder der Initiative "Menschen für Menschen“.

Wenn man sich ein wenig im Land auskennt, wird man über Empfehlungen jederzeit gut ausgebildete Handwerker finden. So wurden in der Bau- und Einrichtungsphase des HITM Handwerker engagiert, die erste Baumängel am Gebäude beglichen haben. Auch die im HITM beschäftigten Ärzte haben geholfen, wo immer eine Hand benötigt wurde. So verfügt das HITM heute unter anderem über regendichte Fenster im Labortrakt, einen abwaschbaren, desinfizierbaren Fußboden und eine stabile Stromversorgung. 


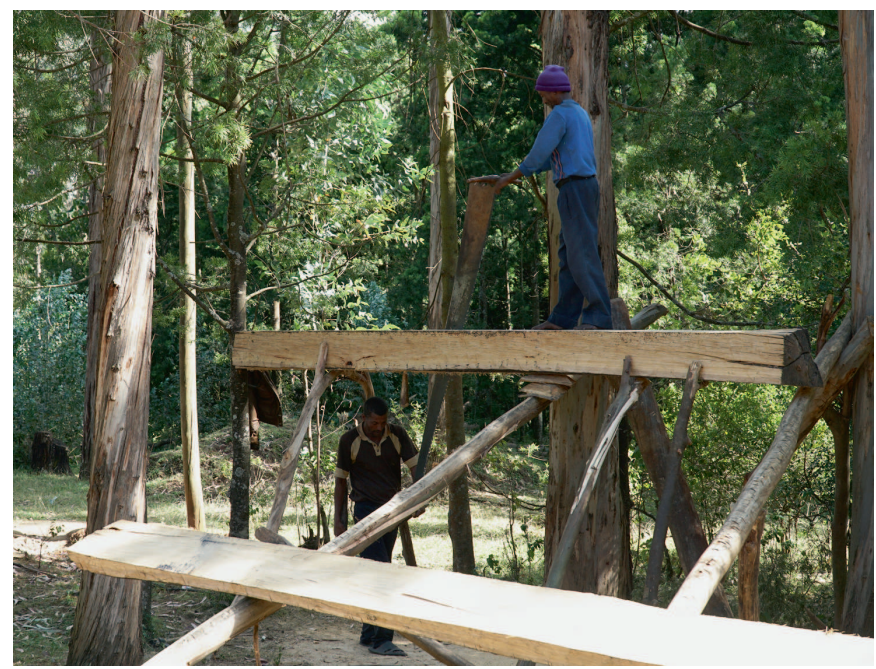

Vieles ist in Äthiopien immer noch Handarbeit. So wie hier z. B. das Zurechtsägen von Brettern als Bauholz aus Eukalyptus-Stämmen

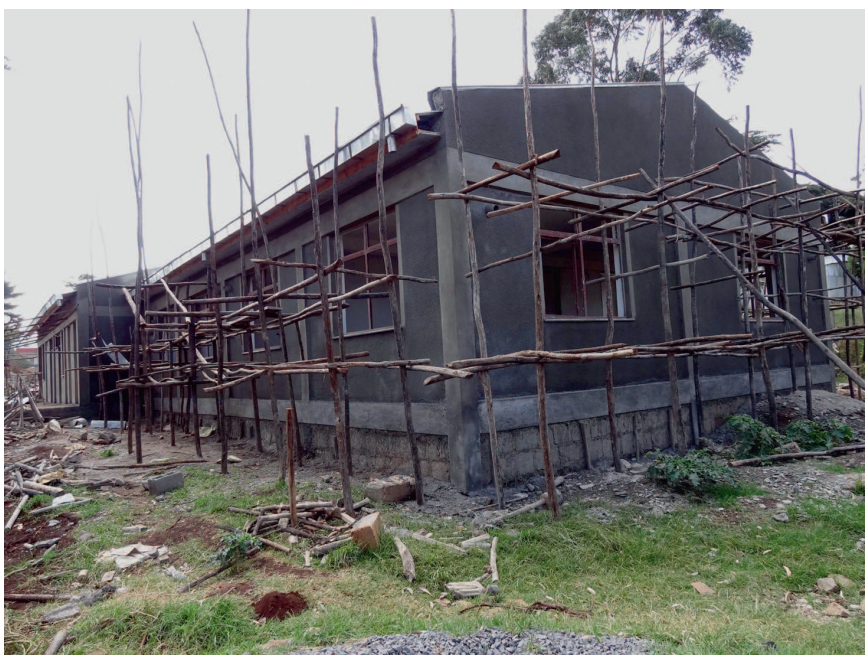

Der traditionell eingerüstete Rohbau des Hirsch-Instituts im Jahr 2011 